\title{
Open vs. closed syllable phonology and temporal production in Greek
}

\author{
Anthi Chaida ${ }^{1,2}$, Ilectra Dimoula ${ }^{2}$, Evgenia Magoula ${ }^{2}$, Olga Nikolaenkova ${ }^{3}$ \\ ${ }^{1}$ Lab of Phonetics \& Computational Linguistics, University of Athens, Greece \\ ${ }^{2}$ Department of Primary Education, University of Athens, Greece \\ ${ }^{3}$ Department of General Linguistics, Saint Petersburg State University, Russia \\ https://doi.org/10.36505/ExLing-2017/08/0008/000310
}

\begin{abstract}
The present experimental study examines syllable constituent durations as a function of syllable structure, lexical stress and focus. In accordance with a production experiment, the results indicate that both syllable structure and lexical stress have significant effects on syllable constituent durations but not focus. Syllable structure has a compensatory temporal effect, according to which open syllables have longer nucleus vowels but shorter onset consonants in comparison to closed syllables. Lexical stress has a lengthening effect on all syllable constituents, in the order nucleus vowel > onset consonant > coda consonant. Onset consonants and nucleus vowels showed significant interactions between syllable type and lexical stress, which indicates extensive variability of segment duration in accordance with prosodic structure and prosodic context of spoken utterances.
\end{abstract}

Key words: consonant, vowel duration, syllable, temporal production, Greek

\section{Introduction}

The present study is an experimental investigation of segment durations as a function of open vs. closed syllable structure as well as lexical stress and focus.

Research on different languages has concentrated on vowel nucleus duration, suggesting that vowels in open syllable context are longer than respective vowels in closed syllable context (Maddieson 1985). The vowel lengthening effect of open syllabicity has even been phonologised in Swedish, where open syllables have phonological long vowels whereas closed syllables have phonological short vowels. This open syllable vowel lengthening effect, either phonological or phonetic, remains an open issue as results from different studies have been fairly controversial (McCrary 2004).

In this study, in addition to the open vs. closed syllable temporal variability of vowel nucleus, considerable attention is paid to each and every syllable constituent, including syllable onset in both open and closed syllable contexts as well as syllable coda in closed syllable contexts. Another aspect, which has hardly drawn particular attention in the international literature, is the effect of variable prosodic conditions, particularly lexical stress and focus, on each syllable constituent.

ExLing 2017: Proceedings of 8th Tutorial and Research Workshop on Experimental Linguistics, 19-22 June, Heraklion, Crete, Greece 


\section{Experimental methodology}

The speech material consists of four test words: two in nominative singular and two in accusative plural with lexical stress at the antepenultimate and penultimate, respectively (Table 1 ). The test words were produced at the context of the carrier phrase ['fonakse ðina'ta] 's/he shouted

loudly'. Five female speakers at their early twenties, with standard Athenian Greek pronunciation, produced the speech material at a normal tempo in focus and out of focus contexts in a sound-treated studio at Athens University Phonetics laboratory. The speech material was analysed with the Praat programme and the results of segment duration measurements were subjected to statistical processing with SPSS statistical package.

Table 1. Test words in nominative and accusative with lexical stress assignment in antepenultimate and penultimate syllable, respectively.

\begin{tabular}{|l|l|l|}
\hline Nominative singular & Accusative plural & Gloss \\
\hline 'sineetos & sin' 'etus & Synthetic \\
\hline 'sisomos & si'somus & Whole \\
\hline \hline
\end{tabular}

\section{Results}

The results are shown in figures 1-3. In accordance with a three-way Anova (syllable type $\mathrm{x}$ lexical stress $\mathrm{x}$ focus), syllable type and lexical stress have significant effects on both onset consonant and vowel nucleus durations whereas focus has no significant effect on any syllable constituent.

Figure 1 shows mean durations of syllable type constituents. Onset consonant in open syllables is $89 \mathrm{~ms}$ (SD 20) and in closed syllables $97 \mathrm{~ms}$ and this difference of $8 \mathrm{~ms}$ is significant $(\mathrm{F}=4.5, \mathrm{p}<0.03)$. Nucleus vowel in open syllable is $76 \mathrm{~ms}$ (SD 22) and in closed syllable $55 \mathrm{~ms}$ and this difference of $22 \mathrm{~ms}$ is also significant $(\mathrm{F}=30, \mathrm{p}<0.0001)$.

Figure 2 shows mean durations of syllable constituents as a function of lexical stress application. Stressed syllables are $219 \mathrm{~ms}$ (SD 30) and unstressed syllables $147 \mathrm{~ms}$, a significant difference of $72 \mathrm{~ms}(\mathrm{~F}=129$, $\mathrm{p}<0.0001$ ). Onset consonants in stressed syllables are $107 \mathrm{~ms}$ and in unstressed syllables $79 \mathrm{~ms}$, a significant difference of $28 \mathrm{~ms}$ ( $\mathrm{F}=97$, $\mathrm{p}<0.0001)$. Vowel nucleus in stressed syllables are $82 \mathrm{~ms}$ and in unstressed syllables $47 \mathrm{~ms}$, a significant difference of $35 \mathrm{~ms}(\mathrm{~F}=133, \mathrm{p}<0.0001$. Coda consonants in stressed syllables are $57 \mathrm{~ms}$ and in unstressed syllables $47 \mathrm{~ms}$, a significant difference of $10 \mathrm{~ms}(\mathrm{~F}=11, \mathrm{p}<0.01)$.

Figure 3 shows mean durations of syllable constituents as a function of focus application. Although syllables and syllable constituents in focus are 
slightly longer than respective syllables and syllable constituents out of focus, any duration differences do not reach significance level.

The results indicate significant interactions of syllable type $\mathrm{x}$ lexical stress with reference to onset consonant $(\mathrm{F}=4.2, \mathrm{p}<0.04)$ but not any other syllable constituent.

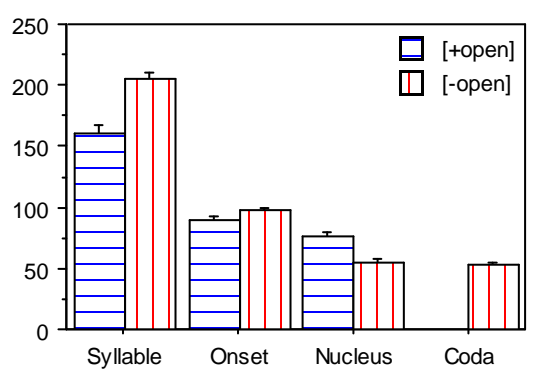

Figure 1. Onset, nucleus and coda syllable constituent durations (in ms) as a function of open (+open) vs. closed (-open) syllable type.

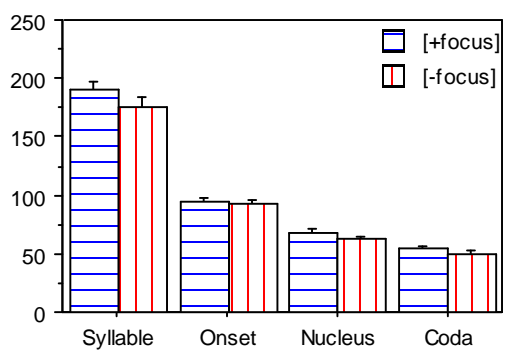

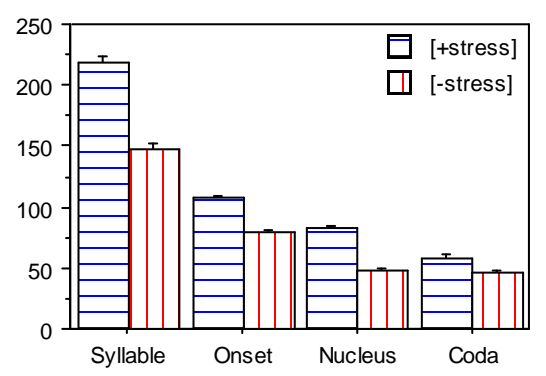

Figure 2. Syllable, onset, nucleus and coda constituent durations (in ms) as a function of stressed (+stress) vs. unstressed (-stress) syllables.

Figure 3. Syllable as well as onset, nucleus and coda constituent durations (in $\mathrm{ms}$ ) as a function of focus (+focus) vs. out of focus (-focus) context.

\section{Discussion and conclusions}

The present study has produced new findings as well as corroboration of earlier results. The new findings are related to (1) the onset consonant and nucleus vowel compensatory duration tendencies, i.e. open and closed syllabicity implies onset consonant and nucleus vowel mirror-image duration pattern and (2) the variability of lexical stress lengthening effects according to syllable structure constituency, i.e. vowel nucleus > onset consonant > coda consonant. On the other hand, the lengthening effect of lexical stress application on onset consonant and vowel nucleus as well as the absence of any lengthening effect of focus application on any syllable constituent have been corroborated (Botinis 1989, Fourakis, Botinis, Katsaiti 1999). 
A widely discussed phonetic correlate of syllable structure is duration variability, according to which open and closed syllables show respective tendencies of increased and decreased vowel durations (Maddieson1985). In Swedish, vowel length is claimed to be distinctive, in accordance with a rhyme VC complementary distribution. Thus, short vowels (V) are followed by long (geminate) consonants or consonant clusters (CC) and long vowels (V:) are followed by short (singleton) consonants (C), which results to VC.C vs. V:.C (VV.C) syllable structures, e.g. "vil:a" (villa) "vi:la" (rest). In Italian, on the other hand, consonant length is claimed to be distinctive and a question is thus raised in respect to the preceding vowel length (Bertinetto 2004, Farnetani and Kori 1986). Several studies report on vowel lengthening as a function of open syllabicity, e.g. "ca:ne" (dog), and vowel shortening as a function of close syllabicity, e.g. "car.ne" (meat) (Farnetani and Kori 1986). On the other hand, Farnetani and Kori (1986) report consonant lengthening at coda position, which is in complementary distribution with vowel duration.

Regardless the phonological status of consonants or vowels and their respective duration correlates in Italian and Swedish, Greek has no consonant or vowel length distinctions and any variability of segment durations is phonetic at segment level. On the other hand, as the results of the present study imply, segment durations reflect different syllable constituents, which are phonological rather than phonetic at syllable level.

\section{Acknowledgements}

Thanks to Yi Xu for comments and much useful feedback as well as Maria Papanagiotou and Athina Tsiori for data recordings and data analysis. The Special Account for Research Grants, National and Kapodistrian University of Athens, has granted research and travel allowance.

\section{References}

Bertinetto, P.M. 2004. On the undecidable syllabification of /sC/ clusters in Italian: Converging experimental evidence. Italian Journal of Linguistics / Rivista di Linguistica, 16, 349-372.

Botinis, A. 1989. Stress and Prosodic Structure in Greek. Lund University Press.

Farnetani, E. and Kori, S. 1986. Effects of syllable and word structure on segmental durations of spoken Italian. Speech Communication 5, 17-34.

Fourakis, M., Botinis, A., Katsaiti, M. 1999. Acoustic characteristics of Greek vowels. Phonetica 56, 28-43.

Maddieson, I. 1985. Phonetic cues to syllabification. In Fromkin, V. (ed.), Phonetic Linguistics, 203-221. London: Academic Press.

McCrary, K.M. 2004. Reassessing the role of the syllable in Italian phonology: An experimental study of consonant cluster syllabification, definite article allomorphy and segment duration. Ph.D. thesis, UCLA. 